Wright State University

CORE Scholar

5-1-1994

\title{
Low-Temperature Growth of High Resistivity GaAs by Photoassisted Metalorganic Chemical Vapor Deposition
}

\author{
J. C. Roberts \\ K. S. Boutros \\ S. M. Bedair \\ David C. Look \\ Wright State University - Main Campus, david.look@wright.edu
}

Follow this and additional works at: https://corescholar.libraries.wright.edu/physics

Part of the Physics Commons

\section{Repository Citation}

Roberts, J. C., Boutros, K. S., Bedair, S. M., \& Look, D. C. (1994). Low-Temperature Growth of High Resistivity GaAs by Photoassisted Metalorganic Chemical Vapor Deposition. Applied Physics Letters, 64 (18), 2397-2399.

https://corescholar.libraries.wright.edu/physics/50

This Article is brought to you for free and open access by the Physics at CORE Scholar. It has been accepted for inclusion in Physics Faculty Publications by an authorized administrator of CORE Scholar. For more information, please contact library-corescholar@wright.edu. 


\title{
Low-temperature growth of high resistivity GaAs by photoassisted metalorganic chemical vapor deposition
}

\author{
J. C. Roberts, K. S. Boutros, and S. M. Bedair \\ Department of Electrical and Computer Engineering, North Carolina State University, Raleigh, \\ North Cirolina 27695-7911 \\ D. C. Look \\ University Research Center, Wright State University, Dayton, Ohio 45435
}

(Received 1s November 1993; accepted for publication 9 February 1994)

\begin{abstract}
We report the photoassisted low-temperature (LT) metalorganic chemical vapor deposition (MOCVD) of high resistivity GaAs. The undoped as-grown GaAs exhibits a resistivity of $\sim 10^{\mathrm{f}}$ $\Omega \mathrm{cm}$, which is the highest reported for undoped material grown in the MOCVD environment. Photoassisted growth of doped and undoped device quality GaAs has been achieved at a substrate temperature of $400^{\circ} \mathrm{C}$ in a modified atmospheric pressure MOCVD reactor. By using silane as a dopant gas, the LT photoassisted doped films have high levels of doping and electron mobilities comparable to those achieved by MOCVD for growth temperatures, $T_{8}>600{ }^{\circ} \mathrm{C}$.
\end{abstract}

Recently, there has been considerable interest in lowtemperature (LT) GaAs deposited at $200^{\circ} \mathrm{C}$ by the molecular beam epitaxy (MBE) technique. These LT GaAs films, which become highly resistive $\left(p-10^{6} \Omega \mathrm{cm}\right)$ after being annealed above $500^{\circ} \mathrm{C}$, have found several device applications such as semi-insulating buffer materials for metal-semiconductor field-effect transistor (MESFET) structures, ${ }^{1,2}$ insulating layers in metal-insulator-semiconductor ficld-effect transistor (MISFET) structures, ${ }^{3,4}$ and as materials for photoconductive switches and photodetectors. ${ }^{5.6}$ With growth rates of $1 \mu \mathrm{m} / \mathrm{h}$, even at growth temperatures $\left(T_{g}\right)$ as low as $200^{\circ} \mathrm{C}$, the $\mathrm{MBE}$ approach has been the only method of depositing LT GaAs material. Less attention has been focused on the properties of GaAs grown by metalorganic chemical vapor deposition (MOCVD) at low temperatures. Semi-insulating LT GaAs films grown by MOCVD have not yet been reported probably due to the decrease in growth rate for $T_{y}$ below $-450{ }^{\circ} \mathrm{C} .{ }^{7}$ Enhancement of the low GaAs growth rate inherent in low-temperature MOCVD can be addressed by applying additional stimuli such as photons and plasmas which induce the growth process to proceed more efficiently. The specific nature of the extra applied growth stimulus, be it the wavelength of photons or energy of a plasma, may interact with the reactants and/or substrate to give rise to material properties that would not normally be expected in conventional (higher temperature) MOCVD growth. We will report on the growth of highly resistive/semi-insulating GaAs selectively deposited with a growth rate exceeding $1 \mu \mathrm{m} / \mathrm{h}$ by photoassisted MOCVD at low temperatures. We will also discuss the $n$-type doping that is exhibited by these GaAs films at these low growth temperatures.

Our photoassisted MOCVD apparatus consists of a vertical MOCVD reactor operated at atmospheric pressure, an Ar ion laser operated at multiple wavelength $(488-514 \mathrm{~nm})$ and a computer controlled $X-Y$ laser beam scanner $(2-3 \mu \mathrm{m}$ resolution). An optical grade quartz window, welded onto our cylindrical $\mathrm{SiO}_{2}$ growth tube, admits the incoming laser light. The complete growth tube assembly is mounted on an optical table for vibration isolation. Other details of the ex- perimental apparatus have been reported elsewhere where several other device structures such as $p-i-n$ 's and MESFETs have been achieved. ${ }^{9,10}$ Semi-insulating GaAs wafers, $2^{\circ}$ off $(100)$ toward [110], were solvent cleaned, etched, and attached to a graphite susceptor which was if heated to a growth temperature in the $300-400^{\circ} \mathrm{C}$ range. A quartz tube sealed at one end, which completely supports the susceptor, has a thermocouple inserted in it to monitor the growth temperature. Trimethylgallium (TMG, $-10^{\circ} \mathrm{C}$ ) and arsine $\left(\mathrm{AsH}_{3}, 100 \%\right)$ were used as source gases. The $\mathrm{Ar}$ ion laser, focused to a spot size of approximately $500 \mu \mathrm{m}$, was multiple scanned over a local area of the substrate for a distance of about $1 \mathrm{~mm}$ at a scanning speed of $-200 \mu \mathrm{m} / \mathrm{s}$. The laser power density was maintained between 900 and 1000 $\mathrm{W} / \mathrm{cm}^{2}$. By repeatedly scanning the focused $\mathrm{Ar}$ ion laser beam across the thermally biased substrate in the presence of an organometallic compound and arsine, maskless selective epitaxy of GaAs is induced only at those areas exposed to the laser. Negligible growth occurs outside of the laser irradiated area. The photodeposited film thicknesses, measured with a Tencor $\alpha$-step microstylus profilometer, are found to have Gaussian-like cross sections, which may be attributed to the Gaussian laser beam intensity profile. Typical growth rates obtained with our growth conditions, based on the maximum thickness of the Gaussian profilc, are 15-20 $\AA / \mathrm{scan}$, which translates to $\sim 1.4 \mu \mathrm{m} / \mathrm{h}, N$-type doping was achieved by using silane ( $\mathrm{SiH}_{4}, 1000 \mathrm{ppm}$ in $\mathrm{H}_{2}$ ).

Resistivity and Hall effect measurements were performed on $450 \mu \mathrm{m}$ by $150 \mu \mathrm{m}$ van der Pauw mesas which were photolithographically defined and then etched onto the laser-grown material. Four ohmic contacts, consisting of $1000 \AA \mathrm{Au} / \mathrm{Ge}, 300 \AA \mathrm{Ni}$, and $1500 \AA \mathrm{Au}$, were joined to the mesas at the corners and annealed in a $\mathrm{N}_{2}$ ambient at $400{ }^{\circ} \mathrm{C}$ for $1.5 \mathrm{~min}$. The Gaussian shaped cross section of the deposited films results in a thickness variation of $-20 \%$ across the van der Pauw mesa. We have used the maximum film thickness in our Hall measurement calculations which will result in an underestimating of about $10 \%$ in the carrier concentration but with negligible error for mobility data. 


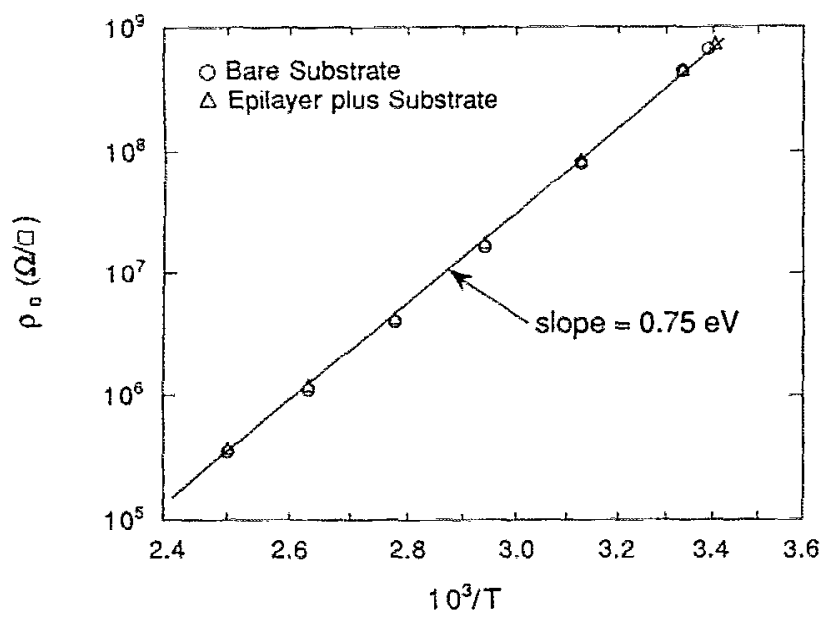

FIG. 1. Resistivity vs inverse $T$ data.

Resistivity versus inverse $T$ data for two samples are shown in Fig. 1. The triangles show results for a $1.6 \mu \mathrm{m}$ thick undoped $\mathrm{GaAs}$ film grown at $400^{\circ} \mathrm{C}$, while the circles show results of a bare substrate (for comparative purposes). Clearly there is no difference within experimental error between the layered substrate and the bare substrate, showing that the epilayer adds no measurable conductance. In such a case, accurate measurements can be obtained only by separating the epilayer from the substrate, as has been recently done for LT MBE layers; ${ }^{\prime \prime}$ however, in this case the sample was too small to permit a separation procedure. To obtain a lower limit on the resistivity we note from Fig. 1 that the two sheet-resistance curves certainly differ by less than $1 \times 10^{8}$ $\Omega / \square$ at room temperature. Thus, the sheet resistance of the layer is greater than about $4 \times 10^{9} \Omega / \square$ which gives a resistivity of about $-10^{6} \Omega \mathrm{cm}$ for a thickness of $1.6 \mu \mathrm{m}$. Of course, we are ignoring depletion effects here, which could be important since the usual $0.7 \mathrm{~V}$ surface potential will deplete the free carriers in about $1 \mu \mathrm{m}$ of GaAs doped at the $10^{15} \mathrm{~cm}^{-3}$ level. ${ }^{12}$ Therefore, what can be inferred is that a LT MOCVD layer of 1-2 $\mu \mathrm{m}$ thickness will add a parallel conductance of less than $3 \times 10^{-10} \Omega^{-1} / \square$ to the usual semiinsulating substrate, a negligible amount for most device applications.

We have also investigated the enhancement of dopant incorporation ( $\mathrm{Si}$ from $\mathrm{SiH}_{4}$ ) occurring during the LT photoassisted growth technique. From the standpoint of device applications, it is desirable for a low-temperature growth process to be capable of doping the as-grown material so that structures can be grown uninterrupted without having to stop the growth to change the substrate temperature. In the MBE environment, the doping efficiency of Si falls off rapidly for $T_{g}$ below $400-450^{\circ} \mathrm{C}$, although the migration-enhanced epitaxy (MEE) technique can push this doping threshold down to $300{ }^{\circ} \mathrm{C} .{ }^{13}$ Silicon doping in conventional MOCVD is typically achieved by using silane $\left(\mathrm{SiH}_{4}\right)$ or disilane $\left(\mathrm{Si}_{2} \mathrm{H}_{6}\right)$ as the dopant gas. For $550^{\circ} \mathrm{C}<T_{g}<800{ }^{\circ} \mathrm{C}$, these dopant sources have been used effectively to obtain high quality material with excellent mobility. ${ }^{14}$ However, for $T_{g}<500{ }^{\circ} \mathrm{C}$, Si doping in conventional MOCVD seems to be less effec-

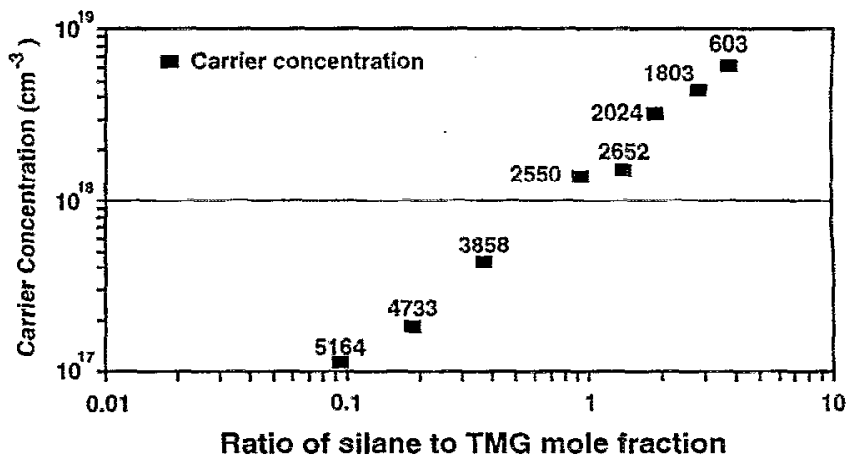

FIG. 2. Eilectron carrier concentration (cm ${ }^{3}$ ) vs ratio of silane to TMG nole traction.

tive. Although $\mathrm{Si}$ incorporation using $\mathrm{Si}_{2} \mathrm{H}_{6}$ shows little temperature dependence at higher $T_{g}$, ${ }^{15}$ the diminished growth rate for $T_{g}<500{ }^{\circ} \mathrm{C}$ makes growth impractical.

Doping experiments were performed by introducing silane into the fluxes of $\mathrm{TMG}$ and $\mathrm{AsH}_{3}$ while scanning the laser across the thermally biased $\left(T_{g}=400^{\circ} \mathrm{C}\right)$ substrate. Hall data of these doped samples are shown in Fig. 2, which plots carrier concentration versus silane/TMG mole fraction. Room-temperature mobilities of each film are indicated beside each data point. The carrier concentration has a linear dependence to the molar ratio of silane to TMG. The slope of a line drawn through the data points is nearly unity, corresponding to a direct proportionality between dopant in the gas phase and silicon incorporation. The room-temperature mobilities increase steadily from $-600 \mathrm{~cm}^{2} / \mathrm{Vs}$ for the higher doped films to more than $5000 \mathrm{~cm}^{2} / \mathrm{V}$ s for the lightest doped film. Mobilities measured at $77 \mathrm{~K}$ show little variation from the RT values. These samples highlight several important points. First, even at $T_{g}=400^{\circ} \mathrm{C}$, the Si doping level can be accurately controlled over nearly two orders of magnitude with silane as the dopant gas. Second, room-temperature mobilities are high enough in these doped films to fabricate useful devices. Third, the growth rates of the $\mathrm{Si}$ doped films at this low temperature are not adversely affected, as others have reported previously. ${ }^{16}$ Last, we detected no conductance on the substrate outside of the laser irradiated area, indicating that the doping is very selective. It should also be mentioned that with this photoassisted LT growth, GaAs films have doping levels as high as $7 \times 10^{18} \mathrm{~cm}^{-3}$ and RT mobilities that are comparable to those achieved by conventional MOCVD grown films at $T_{g}>600^{\circ} \mathrm{C}$.

The nature of the photoenhanced growth and how it is related to the high resistivity and doping level exhibited by the as-grown material is not clear. The process cannot be considered purely pyrolytic since the growth rate of conventional MOCVD GaAs at $400-450^{\circ} \mathrm{C}$ is almost an order of magnitude lower than the current result. If the process is controlled by a photocatalytic reaction, the role of the laser wavelength and hot GaAs substrate surface is not clear regarding the relative efficiency of TMG versus $\mathrm{AsH}_{3}$ cracking. It may be possible that nonstoichiometric growth, with excess As, can be achieved (our V/III ratio, based on the input flow rates of TMG and $\mathrm{AsH}_{3}$, is $\sim 200$ ). It is expected 
however that this excess As would only contribute to the formation of antisite defects. These antisite defects and the associated deep levels can be the origin of the high resistivity, consistent with the semi-insulating MBE films grown at $400{ }^{\circ} \mathrm{C} .{ }^{17}$ It should be noted that while $T_{8}=400^{\circ} \mathrm{C}$ may not be considered low in MBE growth, it must be considered low relative to the MOCVD environment since negligible growth would occur at this temperature in conventional MOCVD. We do not expect As precipitates to be found in our films due to the relatively high growth temperature (compared to the $200^{\circ} \mathrm{C}$ used in LT MBE) and lack of anneal. This is consistent with the reported observed decrease in the density and volume of As clusters in GaAs grown at higher MBE growth temperatures, even after $600^{\circ} \mathrm{C}$ anneals..$^{18}$ It also seems that this suspected photocatalytic process enhances the incorporation of Si to the extent that electron carrier concentrations comparable to conventional MOCVD $\left(T_{8}>600^{\circ} \mathrm{C}\right)$ can be achicved. The low $77 \mathrm{~K}$ mobility of our doped films may bc attributed to scattering centers due to this low-temperature growth process.

The photoassisted growth process constitutes an in situ, maskless. direct-write epitaxial growth technique that can deposit device quality GaAs at a reduced growth temperature which can have electrical properties ranging from highly resistive to highly doped. Thus, highly resistive device quality GaAs grown by photoassisted MOCVD could offer an alternative source to the LT MBE GaAs. Not only does the lasergrown GaAs not require an annealing step to become highly resistive (as does $200^{\circ} \mathrm{C} \mathrm{MBE} \mathrm{GaAs}$ ), but it can also be efficiently doped at this low growth temperature with silane, with comparable room-temperature mobilities to those achieved by the conventional high-temperature MOCVD process.

The authors would like to thank the National Science Foundation, Office of Naval Research, and the National Re- newable Energy Laboratory for supporting this work. Also, thanks are due T. A. Cooper for electrical measurements and L. V. Callahan for technical assistance. D. C. L. Was supported under USAF Contract F33615-91-C-1765 and his work was pertormed at the Solid State Electronics Directorate, Wright Laboratory, Wright-Patterson Air Force Base.

${ }^{1}$ F. W. Smith, A. R. Calawa, C.-L. Chen, M. J. Manfta, and L. J. Mahoney, IEEE Electron Device Lett. 9, 77 (1988).

${ }^{2}$ P. M. Solomon, S. L. Wright, and F. J. Canora, ItEE Electron Device Lett. 12, 117 (1991)

${ }^{3}$ C.-L. Chen, F. W. Smith, B. J. Clifton, L. J. Mahoney, M. J. Manfra, and A. R. Calawa, IEEE Electron Device Lett. 12, 306 (1991).

${ }^{4} \mathrm{~L},-W$. Yin, Y. Hwang, J. H. Lee, R. M. Kolbas, R. J. Trew, and U. K. Mishra, IEEE Electron Device Lett. 11, 561 (1990).

M. Y. Frankel, J. F. Whitaker, G. A. Mourou, F. W. Smith, and A. R. Calawa, IEEE Trans. Electron Device 37, 2493 (1990).

"A. C. Warren, J. H. Burroughes, J. M. Woodall, D. T. McInturff, R. T. Hodgson, and M. R. Melloch, IEEE Electron Device Lett. 12, 527 (1991).

${ }^{7}$ D. H. Reep and S. K. Ghandhi, J. Electrochem. Soc. 130, 675 (1983).

A. D. Huelsman, R. Reif, and C. G. Fonstad, Appl, Phys. Lett. 50, 206 (1987).

${ }^{9}$ H. L iu, J. C. Roberts, J. Ramdani, and S. M. Bedair, Appl. Phys, Lett. 58, 388 (1991).

${ }^{11}$ H. Liu, J. C. Roberts, J. Ramdani, and S. M. Bedair, Appl. Phys. Lett. 58, 1659 (1991).

${ }^{11}$ D. C. Look, D. C. Walters, G. D. Robinson, J. R. Sizelove, M. G. Mier, and C. F. Stutz, J. Appl. Phys. 74, 306 (1993).

${ }^{12}$ D. C. Look, Flectrical Characterization of GaAs Materials and Devices (Wilcy, New York, 1989), p. 47.

${ }^{13}$ B. Tadayon, S. Tadayon, M. G. Spencer, G. I. Harris, T. Griffin, and L. F. Eastman, J. Appl. Phys. 67, 589 (1990).

${ }^{14}$ T. F. Kuech, B. S. Meyerson, and E. Veuhoff, Appl. Phys. Lett. 44, 986 (1984).

${ }^{15}$ T. F. Kuech, E. Veuhoff, and B. S. Meyerson, J. Cryst. Growth 68, 48 (1984).

${ }^{11}$ C.-W. Liu, S.-L Chen, J.=P. Lay, S.-C. Lee, and H.-H. Lin, Appl. Phys. Lett. 51, 1634 (1987).

${ }^{17}$ D. C. Look, G. D. Robinson, J. R. Sizelove, and C. E Stutz, Appl. Phys. Lett. 62, 3004 (1993).

${ }^{18} \mathrm{~K}$. Mahalingam, N. Otsuka, M. R. Melloch, J. M. Woodall, and A. C. Warren, J. Vac. Sci. Technol. B 9, 2328 (1991). 